Egyptian

Orthodontic Journal

\title{
CLINICAL EVALUATION OF OPEN- FACE FIXED SPACE MAINTAINERS
}

\author{
Nagwa A. Ghoname*
}

ABSTRACT:

Early loss of primary molar may cause a problem for the arch development. The most confident way to prevent the space loss in the dental arches is through the use of space maintainers. Parallel to the improvements in resin composite materials and adhesive systems, there have been innovations in the techniques used for the application of space maintainers in the mouth. The aim of this study was to evaluate the clinical performance of fixed space maintainers combined to open-face stainless steel crowns. For this study, thirteen children having premature loss of primary first or second molar teeth were selected from Pedodontic Clinic, Faculty of Dentistry, Tanta University. Crowns were placed on problematic abutment primary teeth; fixed space maintainers were prepared using $0.9 \mathrm{~mm}$ Stainless steel orthodontic wire between the window in the facial surface of the crowns and other abutment teeth and were subsequently bonded with flow able composite resin, and the cases were observed over a period of twelve months. The results showed that two space maintainers failed with $84.62 \%$ clinical performance rate. There was no significant difference between the initial and final distances measured between the abutment teet $h$ to which the space maintainers were bonded ( $P>0.05)$. In conclusion: The study showed the effectiveness of open-face fixed space maintainers placed on the primary molar teeth used as abutment in cases with extensive caries or loss of tooth structure. Open-face fixed space maintainers have high retention and looks more esthetic.

\footnotetext{
*Assistant Professor of Pedodontics, Faculty of Dentistry, Tanta University
} 
Egyptian

Orthodontic Journal

\section{INTRODUCTION}

Primary teeth play an important role for maintaining the space in the dental arches for permanent teeth. The change from primary dentition to the permanent dentition is a complex phenomenon, which is composed of variety of physiological adaptations of occlusion during this period. Thus, the exfoliation of primary teeth, the permanent teeth eruption and the occlusion occur in a harmonious sequence. ${ }^{(1,2)}$

The premature loss of primary teeth is of concern not only because of the loss of function, but also because of the increased possibility of reduce the arch length required for the succeeding teeth, hence predisposes crowding, rotation, and impaction of permanent teeth. ${ }^{(3,4)}$ On the other hand, although there has been some decrease in the rate of premature tooth loss due to the advances in the field of preventive dentistry, this issue still remains a problem and requires further management. ${ }^{(5)}$ The most confident way to prevent the space loss in the dental arches is through the use of space maintainers. The use of these appliances, prompted by the untimely loss of primary tooth, can prevent or reduce the severity of a developing malocclusion. ${ }^{(6,7)}$

Various types of space maintainers have been used to cope with these problems and to protect the mesiodistal relationships of the teeth. ${ }^{(8,9)}$ The goals of the space maintainers are to maintain spaces within the arch as a guiding for eruption of successor teeth, stabilize and prevent drifting of the adjacent teeth and at the same time not interfere with eruption of the permanent teeth. ${ }^{(10-12)}$

Parallel to the improvements in resin composite materials and adhesive systems, there have also been innovations in the techniques used for application of space maintainers. ${ }^{(13-15)}$ Swaine and Wright ${ }^{(16)}$ prepared a fixed space maintainer by using ultra violet light polymerizing resin composite and claimed the rate of failure in their studies was $30 \%$. While, Kirzioglu and Yilmaz ${ }^{(17)}$ used a different bonding system in order to place fixed space maintainers by means of a hybrid resin composite polymerized by visible light cure. They claimed $85.72 \%$ success rate of these fixed space maintainers. 
However, in some cases the existence of caries in a primary tooth used as an abutment or the loss of occlusogingival dimension influenced the survival rate of space maintainers. To overcome such problems crown $\&$ loop space maintainers were recommended. ${ }^{(18)}$ Such space maintainers require some laboratory steps and there is a risk of solder joint failure. ${ }^{(19)}$ In addition, Mockers et $\mathrm{al}^{(20)}$ called attention to the cytotoxic characteristics of solder alloys. Some modifications to crown \& loop or band \& loop were introduced and evaluated clinically. ${ }^{(18,21,22)}$ In these types, orthodontic wire was attached to the molar band or open -face crown with composite resin, so it will be more esthetic.

\section{Aim of the work:}

The aim of this study was to evaluate the clinical performance of fixed space maintainers combined to open- face stainless steel crowns.

\section{MATERIALS AND METHODS}

\section{Subjects:}

A total of 13 children ( 8 girls and 5 boys), whose ages ranged from 6 to 9 years were included in this study The children, presented to Pedodontic Clinic ,Faculty of Dentistry, Tanta University with premature loss of primary first or second molar teeth.

\section{Clinical examination:}

During clinical examinations, the extent of caries, loss of tooth structure of the abutment tooth and the space between the two abutments were evaluated. Caries or old fillings were removed; pulpotomy was done where needed prior to the appliance fabrication

\section{Space Maintainer Design:}

For this study, stainless steel crowns were used to restore the teeth of children in which space maintainers were also indicated. At the same time, fixed space maintainers were attached between the window in the facial surface of the crowns and the other abutment teeth with flowable composite resin. Fig. (1) 
Egyptian

Orthodontic Journal

\section{Method:}

The primary molars to be used as abutment teeth were prepared for stainless steel crowns (3M Dental Products, St Paul, USA).The appropriate crown sizes were selected and the cervical margins adapted tightly to the gingival margins of the preparations, the crowns were then cemented using glass-ionomer cement (Fuji II, GC, America, and Alsip) in accordance with the recommendations of the manufacturer. After cement setting, remnants were removed and a window was created on the vestibular surface of the stainless steel crown, the borders of the window were determined to1-1.5 mm from the mesial and distal contact surfaces and $1 \mathrm{~mm}$ from gingival to the occlusal surface using \# 014 round burs. Fig. (2). After taken the impression of the related jaw, a plaster model was prepared for fabrication of the space maintainer. Fig. (3). The window was filled with a temporary restorative material until the next appointment.

On the prepared plaster model, space maintainer was made of $0.9 \mathrm{~mm}$ stainless steel orthodontic wire, and extended in such a way to touch the facial surface of the abutment teeth. In the next visit, the temporary filling material in the window was removed and the attachment area of the abutment tooth was cleaned, etched with $37 \%$ phosphoric acid( Ultra etch: Ultradent Product, USA), rinsed, dried lightly, and then wetted with light-curing bonding agent ( Perma Quick, Ultradent Product ,Inci USA) according to the manufacturer's recommendation. Space maintainer was attached between the window on the facial surface of the stainless steel crown and the other abutment tooth using light cure Tetric Flow composite resin (Ivoclar Vivadent,FL-9494 Schaan, Lichtenstein). After the polymerization, finishing and polishing were done. Figs. $(4,5,6)$

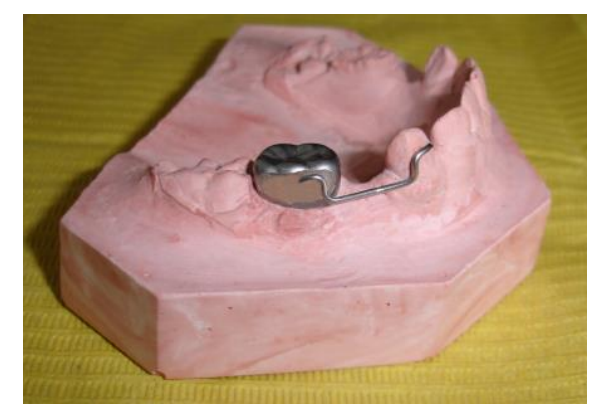

Figure 1. Design of fixed open face Space Maintainer. 


\section{Egyptian}

Orthodontic Journal

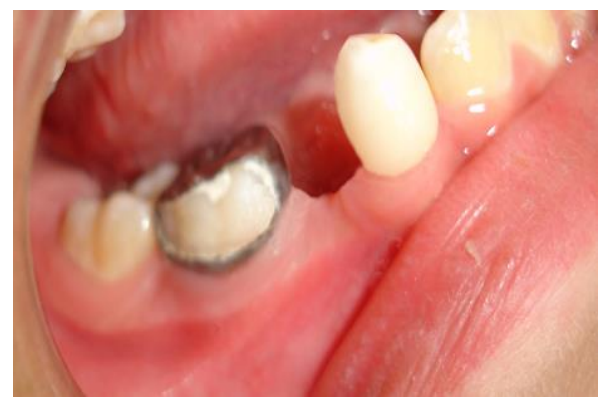

Figure 2. Tooth \# 85 was restored with a stainless Steel crown and window was created on the facial surface of the crown.

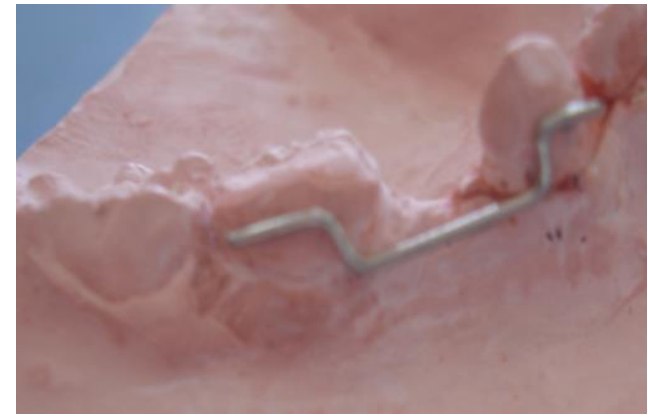

Figure 3. A space maintainer fixed on the plaster model

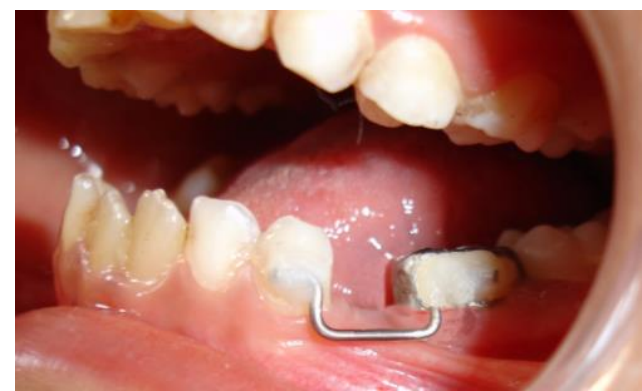

Figure 4. Intraoral view immediately after insertion of the space maintainer bonded on the facial surfaces of teeth \#73 and \# 75 
Egyptian

Orthodontic Journal

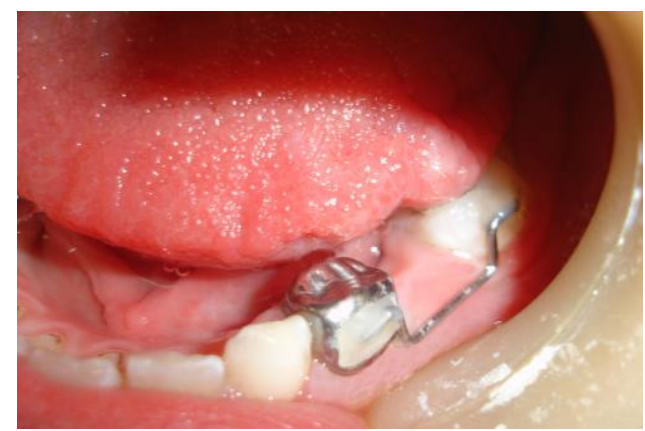

Figure 5. Intraoral view immediately after insertion of the space maintainer bonded on the facial surfaces of teeth \#74 and \# 36

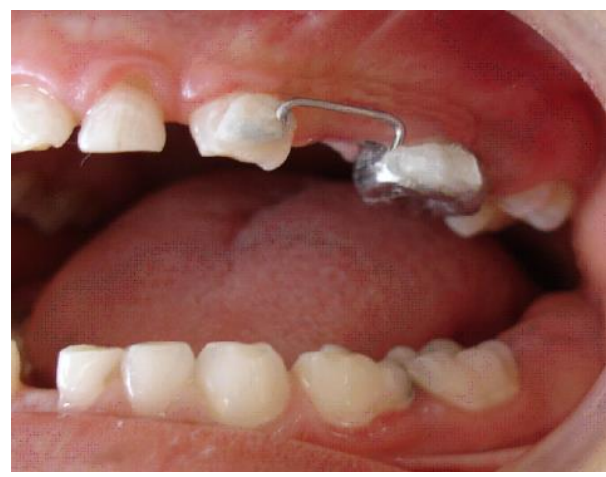

Figure 6. Intraoral view immediately after insertion of the space maintainer bonded on the facial surfaces of teeth \#63 and \# 65.

The appliances were evaluated every three months for one year following placement. During these periodic examinations it was determined whether the space maintainer still existed in the mouth, if there was any decrease in the amount of resin composite used to attach the space maintainer as well as the condition of the abutment teeth.

\section{Measurements:}

The ability of the space maintainer to maintain the space during the study was determined by measuring the distance between the two 
Egyptian

Orthodontic Journal

abutment teeth on the study model by a play gauge (Mesel Dental Dial Caliper, No. 3805 - 100), according to the methods of Swaine and Wright ${ }^{(16)}$. Measurements were obtained as shown in Figure7. Primary-to-primary tooth, in which first primary molar was lost and the stainless steel crown placed on the primary second molar to restore it and to which the space maintainer was attached. Another one was a missing primary second molar with a stainless steel crown placed on the primary first molar to restore it and to which the space maintainer was attached (primary-to-permanent tooth). These measurements were taken to determine whether there was any space change between the initial and final models.

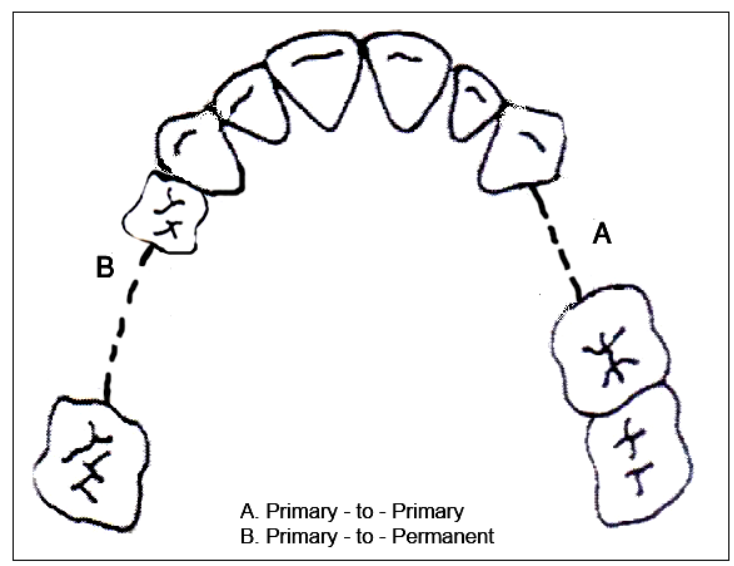

Figure 7. Measurement of space change between the abutment teeth to which space maintainer was attached.

\section{Statistical analysis:}

Data were analyzed using the SPSS package system .Version 10.0, at $5 \%$ level of significant

\section{RESULTS}

Thirteen open-face space maintainers were inserted. The distribution of the appliance in relation to gender, dental arch location and the abutment teeth to which it was bonded are presented in Table1. Throughout the observation periods two cases were clinically failed at the 
composite wire interface, one case after six months and the other one failed after nine months resulting in a clinical success rate of $84.62 \%$. The abutment teeth showed no change during these periods, Table 2.

As shown in Table 3 .There was no significant difference between the initial and final distances between the abutment teeth to which the space maintainers were bonded $(\mathrm{P}=0.180 \& 0.109)$. Table 4 , shows that there was no significant difference in the space change between the primary -to- primary tooth and primary -to- permanent tooth. $(\mathrm{P}=0.122)$.

Table 1. The distribution of space maintainers according to genders, arches and the abutment teeth.

\begin{tabular}{|l|c|}
\hline \multicolumn{1}{|c|}{ Variable } & Distribution \\
\hline Sample size & 13 \\
\hline Girls & 8 \\
\hline Boys & 5 \\
\hline In maxillary arch & 4 \\
\hline In mandibular arch & 9 \\
\hline Primary-to-Primary Tooth & 9 \\
\hline Primary-to-Permanent Tooth & 4 \\
\hline
\end{tabular}

Table 2. The fate of the appliance during observation periods.

\begin{tabular}{|c|c|c|c|c|}
\hline Abutment teeth & N & Success & Failed & Abutment Condition \\
\hline Primary-to-Primary tooth & 9 & 7 & 2 & No change \\
\hline Primary-to-Permanent tooth & 4 & 4 & - & No change \\
\hline Total & $\begin{array}{c}13 \\
100 \%\end{array}$ & $\begin{array}{c}11 \\
84.62 \%\end{array}$ & $\begin{array}{c}2 \\
15.38 \%\end{array}$ & \\
\hline
\end{tabular}

$\mathrm{N}=$ number of space maintainer 
Egyptian

Orthodontic Journal

Table 3. Initial and final distances between the abutment teeth to which the space maintainers were bonded.

\begin{tabular}{|l|c|c|c|c|c|}
\hline \multirow{2}{*}{\multicolumn{1}{|c|}{ Abutment teeth }} & N & Initial space & Final space & \multicolumn{2}{c|}{$\begin{array}{c}\text { Wilcoxon Signed } \\
\text { Ranks Test }\end{array}$} \\
\cline { 3 - 6 } & & Mean \pm SD & Mean \pm SD & $\mathbf{Z}$ & $\mathbf{P}$ \\
\hline $\begin{array}{l}\text { Primary-to-Primary } \\
\text { tooth }\end{array}$ & 7 & $7.729 \pm 0.774$ & $7.700 \pm 0.802$ & -1.342 & 0.180 \\
\hline $\begin{array}{l}\text { Primary-to-Permanent } \\
\text { tooth }\end{array}$ & 4 & $9.400 \pm 0.476$ & $9.200 \pm 0.316$ & -1.604 & 0.109 \\
\hline
\end{tabular}

$\mathrm{N}=$ number of space maintainer

Table 4. The space changes in relation to the abutment teeth.

\begin{tabular}{|l|c|c|c|c|}
\hline \multirow{2}{*}{ Abutment teeth } & \multirow{2}{*}{ N } & Space change & \multicolumn{2}{|c|}{$\begin{array}{c}\text { Mann- Whitney } \\
\text { Test }\end{array}$} \\
\cline { 3 - 5 } & & Mean \pm SD & Z & P \\
\hline Primary-to-Primary tooth & 7 & $0.029 \pm 0.049$ & & \\
\cline { 1 - 3 } Primary-to-Permanent tooth & 4 & $0.200 \pm 0.216$ & & 0.122 \\
\hline
\end{tabular}

$\mathrm{N}=$ number of space maintainer

\section{DISCUSSION}

Management of any space problems associated with the transitional stages from primary to permanent dentition is a routine component of pedodontic practice. ${ }^{(23)}$ The loss of primary teeth before normal physiological exfoliation occurs can result in the collapse of vertical and horizontal occlusal relationships in both primary and permanent dentitions. So, space maintainers are recommended after early loss of primary teeth to prevent such complications. ${ }^{(24,25)}$

Space maintainers are indicated, if the primary molars have premature extraction, when assumption time for the successors to erupt were more than 6 months and there would be enough spaces for the successor teeth according to space analyzes. ${ }^{(26)}$ Fixed space maintainer 
have become an optional to overcome the uncooperative behavior of patient during the treatment with some considerations on the oral hygiene, and also the willingness of patient to worn this device. ${ }^{(27,28)}$ Nevertheless, the occluso-gingival dimension or structure loss of the abutment tooth where fixed space maintainers are to be placed makes the clinical application of space maintainers some what less successful. ${ }^{(18)}$

Previously, crown-loop or band- loop space maintainers were preferred in cases where the abutment teeth had the above mentioned problems. On the other hand, Qudeimat and Fayle ${ }^{(12)}$ reported that cement lost and solder failure are the most common reason for failure in space maintainers. Moreover, these space maintainers have the potential to submerge into the gingivo-alveolar tissues and may lead to tipping and rotation in the abutment teeth. ${ }^{(29)}$

In the present study, stainless steel crowns were placed on a problematic abutment primary teeth creating a window on the facial surface of the crown to make them more esthetic, fixed space maintainer was then bonded between the facial surface of the abutment teeth. Using this technique, the problems as incomplete solder joint ${ }^{(30,31)}$, the overheating of the wire during soldering ${ }^{(19,32)}$, wire thinned by polishing, and the remnants of flux on the wire ${ }^{(33)}$ in crown- loops or band loops space maintainers were avoided. Furthermore, open-face fixed space maintainer was made by means of orthodontic wire, so it would be easy to adjust and prevent the rotation movement of axis wire. ${ }^{(16,21)}$ This modified space maintainer showed high retention and strength, with no tipping movement of the abutment teeth, it looked more esthetic and easily removed from the teeth with the least damage possible at the end of the treatment process.

Confirming the result of the previous investigations, factors relating to appliance construction and cementation may be more important for survival time of the space maintainers. ${ }^{(34)}$ When the fixed space maintainer combined with an open-face stainless steel crowns was indicated, the cement material can be allowed to remain on the exposed surface after removing the facial aspect of the crown to create the window, but the bond strength of modern bonding agents is even higher than that of glass-ionomer cements. ${ }^{(35)}$ Therefore, in the present study, 
Egyptian

Orthodontic Journal

the cement from the window area was removed for better adaptation of composite resin to the prepared cavities during the application of space maintainers.

In the present study, through out the observation periods clinical failure was recorded in two cases $(15.38 \%)$ due to loss of the composite resin. This result coincides with Santos et al ${ }^{(14)}$ who evaluated clinically bonded fixed space maintainer, and reported $8.5 \%$ rate of failure.It can be considered low when compared with the results of Swani and Wright ${ }^{(16)}$ where the failure rate of bonded space maintainer was about $30 \%$.On the other hand, the present study differs from Yilmaz et al. ${ }^{(18)}$ They reported high clinical performance of open-face fixed space maintainers with100\% success rate.

On the observation periods after the appliance placement, space maintainer was stable on its position and there were no complaint from the patients. In addition, no change on the abutment teeth had happened, but there were some plaque accumulations so the patient was advised for improving his oral hygiene.

The effectiveness of the appliance is dependent upon its ability to maintain the space. In the present study, no significant space change was found and the space change was only $0.2 \mathrm{~mm}$ in primary -to- permanent abutment tooth, this may be attributed to the axial inclination of the permanent teeth, some of the chewing forces produce a mesial resultant through the contact point of the teeth " the anterior component of force" in comparison to the primary teeth which is almost in vertical inclination. ${ }^{(1)}$ This agreed with Swaine and Wright. ${ }^{(16)}$ They found that $70 \%$ of direct bonded space maintainers were in position without space loss, and the change in space was less than $0.1 \mathrm{~mm}$ than the other types of space maintainers. While, Yilmaz et al ${ }^{(18)}$ concluded that, there was no significant difference between the initial and final distances between the abutment teeth to which the space maintainers were bonded.

\section{CONCLUSION}

Several space maintainers have been used to prevent the space loss because of premature extraction of primary teeth. Based on the results of 
the present study, it is concluded that open-face space maintainers is simple, stable, and easy to fabricate. Also, it can be used in cases with loss of tooth structure or extensive caries of the abutment.

\section{Acknowledgement:}

I am deeply grateful to professor Dr. Amina Elhosary, Professor of Pedodontics, Faculty of Dentistry, Tanta University for her helpful and generous cooperation

\section{REFERENCES}

1- Moyers RE. Handbook of orthodontics Year Book Medical publishers, inc. Chicago. London $4^{\text {th }}$ ed , 1991; pp107-118.

2- Liegeois F and Limme M. Space maintenance following the premature loss of temporary teeth. Rev Belge Med Dent 1992; 47:9-22.

3- Cardoso L, Zembruski C, Femandes DSC, Boff I and Pessin V. Evaluation of prevalence of malocclusion in relation to premature loss of primary teeth. Pesq Bras Odontoped Clin Integ 2005;5:17-22.

4- McDonald RE, Every DR and Deen JA .Dentistry for Child and Adolescent . $8^{\text {th }}$ ed, St. Louis , Mosby, 2004; pp 625-683.

5- Qudeimat MA and Fayle SA. The use of space maintainers at a UK pediatric dentistry department. J Dent Child 1999 ; 66: 383-386.

6- Mitchell L and Mitchell DA. Oxford handbook of clinical dentistry. ${ }^{\text {rd }}$ ed. Oxford: University Press, 1999; pp 128-198

7- Ghafari, J. Early treatment of dental arch problems. I. Space maintenance, space gaining. Qunit Int 1986; 17:423-432.

8- Qudeimat MA and Fayle SA. The longevity of space maintainers: a retrospective study. Pediatr Dent 1998 ; 20: 267-272.

9- Mathewson RJ and Primosch R E. Fundamentals of Pediatric Dentistry. 3 rd ed. Chicago: Quintessence Publishing Co, Inc, 1995; pp 326-32.

10- Baroni C, Franchini A and Rimondini L. Survival of different types of space maintainers. Pediatr Dent1994; 16:360-361. 
11- Ngan P, Alkire RG and Fields H J. Management of space problems in the primary and mixed dentitions. J Am Dent Asso1999; 130:1330-1339.

12- Terlaje RD and Donly KJ. Treatment planning for space maintenance in the primary and mixed dentition. J Dent Child 2001; 68: 109-114.

13- Artun J and Marstrander PB. Clinical efficiency of two different types of direct bonded space maintainers. J Dent Child 1983 ; 50: 197-204.

14- Santos VLC, Almeida MA, Mello HAS and Keith O. Direct bonded space maintainers. J Clin Pediatr Dent 1993; 17: 221-225.

15- Kargu B, Caglar E and Kabalay U. Glass Fiber-reinforced Composite Resin as Fixed Space Maintainers in Children:12-month Clinical Follow-up. J Dent Child 2005;72:109-11.

16- Swaine TJ and Wright GZ. Direct bonding applied to space maintenance. J Dent Child 1976; 43:21-25.

17- Kirzioglu Z and Yilmaz Y. A longitudinal observation of the simple space maintainers bonded by resin composite (English Abstract). Atatürk Univ Dis Hek Fak Derg. 1999; 9: 47-53.

18- Yilmez Y, Kocogullari E and Belduz N. Fixed space maintainer combined with open face stainless steel crowns. J Contemp Dent Pract 2006; 7(2): 1-8.

19- Hill CJ, Sorenson HW and Mink JR. Space maintenance in a child Dental Program. J Am Den Assoc 1975:90:811-5.

20- Mockers O, Deroze D and Camps J. Cytotoxicity of orthodontic bands, brackets and arch wires in vitro. Dent Mater 2002; 18: 311-317.

21- Horax S .Fixed space maintainer with molar band in premature loss of first primary molar teeth (case report) Med Nus 2006; 27: 174 -176.

22- Simsek S, Yilmaz Y and Gurbuz T. Clinical evaluation of simple fixed space maintainers bonded with flowable composite resin. J Dent Child 2004; 71:163-168.

23-Padma K B and Retna K N .Loss of space and changes in the dental arch after premature loss of the lower primary molar: a longitudinal study. J Indian Soc Pedo Prev Dent 2006; 24: 90-96. 
24- Kisling E and Hoffding J. Premature Loss of Primary Teeth: Part IV, a Clinical Control of Sannerud's space maintainer, Type I.J Dent Child 1979;46:17-21.

25- Lin YT and Chang LC. Spaces after premature loss of the mandibular primary first molar: A longitudinal study. J Clin Pediat Dent 1998; 22: 311-316.

26- Daly D and Walker PO. Space maintenance in the primary and early mixed dentition. J Irish Dent Assoc 1990; 36:16-17s.

27- Proffit W R, Fields H W. Arckerman J L, Bailey TJ and Tulloch C J F. Contemporary Orthodontics,3rd ed. St. Louis: Mosby, Inc;2000, pp 418-21

28- Waggoner WF and Kupietzky A. Anterior esthetic fixed appliances for the preschooler: considerations and a technique for placement. Pediatr Dent 2000; 23:147-150.

29- Croll TP. Prevention of gingival submergence of fixed unilateral space maintainers. J Dent Child1982; 49: 48-51.

30- Davies JA. Dental restoration longevity: a critique of the life table method of analysis. Community Dent Oral Epidemiol 1987; 15: 202-204.

31- Brown RA and Beck JS. Survival analysis. In: Brown RA, Beck JS. Medical Statistics on Persona Computers, Ed. London: BMJ Publishing Group, 1995; pp99-118

32- Thorton JB. The space maintainer: case reports of misuse and failures. Gen Dent.1982; 30: 64-67

33- Wright GZ and Kennedy DB. Space control in the primary and mixed dentitions. Dent Clin North Am1978; 22: 579-601.

34- Tulunoglu O, Ulusu T and Genç Y. An Evaluation of Survival of Space maintainers: A Six-year Follow-up Study. J Contemp Dent Pract 2005;6(1):74- 84.

35- Opdam NJ, Roete JJ, Peters TC, Burgersdijk RC and Teunis M. Cavity wall adaptation and voids in adhesive class I resin composite restorations. Dent Mat 1996;12:230-235. 